\title{
Depression a High Leading Cause for Death - An Alert
}

\section{Seema Mehdi*}

Lecturer, Department of Pharmacology, JSS College of Pharmacy, JSS Academy of Higher Education and Research, Mysuru, India

*Corresponding Author: Seema Mehdi, Lecturer, Department of Pharmacology, JSS College of Pharmacy, JSS Academy of Higher

Education and Research, Mysuru, India.

Received: June 26, 2019; Published: July 152019

DOI: 10.31080/ASNE.2019.02.0081

The stigma attached to the word "depression", a terminology which takes out the pleasure from life, has its own manifestations in bringing up a change in individuals' mood, hence it's also known as a mood disorder. Our day begins with the new hope and that hope comes with a good mood, changes in the mood doesn't go away soon, which is a repetitive occurrence that affects the daily life and takes off the happiness from activities and relationships.

Depression is irrespective of gender, and while the treatment is complicated, the emerging research has to take up the challenge in bringing up an effective and safe treatment for the particular cause, which can be by emphasizing on lifestyle, diet, relationships, employment, psychological and such which may be overlooked.

Depression is most likely to affect women than men and tends to have different contributing causes. Contributing factors include reproductive hormones, a differing female response to stress, and social pressures that are unique to a woman's life experiences.

Adding to this is the loss of interpersonal skills and the ability to connect with another human being in real life which can be attributed to the fast-growing world of an online experience. This ability although overlooked by the young generation could be an important contributing factor to depression.

The level of depression differs from person to person and the same is true with the causes, so the challenge is to understand the cause and to bring out the effective solution by altering the diet, lifestyle and medication. Most of the data is available on this but we still need to emphasise on the newer options, as the digitalization is on its boon, its impact on mental health is also high.
Acta scientific neurology journal is one such platform which can be considered to bring out such research in the area of depression and help out the society in understanding its proper cause and bring up the awareness in young minds.

Volume 2 Issue 8 August 2019

(C) All rights are reserved by Seema Mehdi. 